\title{
Asian American Subgroup Differences in Sources of Health Information and Predictors of Screening Behavior
}

\author{
Steven E. Shive ${ }^{1,2}$, Grace X. Ma ${ }^{2}$, Yin Tan ${ }^{2}$, Jamil I. Toubbeh ${ }^{2}$, \\ Lalitha Parameswaran ${ }^{2}$, Joseph Halowich ${ }^{3}$ \\ ${ }^{1}$ East Stroudsburg University \\ ${ }^{2}$ Temple University Center for Asian Health \\ ${ }^{3}$ Parkside High School
}

\begin{abstract}
This study examined Asian subgroup differences in sources of health information and cancer screening, comparison of Asians and Whites in screening, and the association between health information and screening behavior. A nationally representative sample of 6,722 adults in the US, including those who speak, Chinese, Vietnamese and Korean was selected. Questionnaire items developed by the Commonwealth Fund included demographic variables, health status, cancer screening, health care experiences, health information sources, and use of an interpreter in the patient-provider interaction. There were differences between subgroups in source of health information. Indians from India were more likely to use the World Wide Web than Chinese, Koreans, and Filipinos. There were differences in ease of reading or understanding instructions on the prescription bottle, information booklets provided by physicians, and in difficulty speaking with a physician. There were differences in getting a general physical and a pap test between Asian ethnic subgroups and between Asians and Whites. Certain sources of health information were positively correlated with specific screening tests. Development of particular sources of health information relevant to specific Asian subgroups and for specific screening tests may enhance their decision making prior to and in conjunction with receiving medical care services.
\end{abstract}

(C) 2007 Californian Journal of Health Promotion. All rights reserved.

Keywords: Asian, Cancer information, Cancer Screening, Screening Behavior

Asian Americans are one of the fastest growing minority groups in the U.S., and over the past 30 years their immigration has increased by more than $400 \%$. Asians report less satisfaction with health care (Saha, Arbelaez, \& Cooper, 2003; Saha \& Hickam, 2003), and health insurance coverage (Haviland, Morales, Reise, \& Hays, 2003), as compared to Blacks and Whites. This lack of satisfaction may be attributed to health care disparities between Asians and other racial/ethnic populations. An important factor in healthcare disparities is access to care.

A recent Institute of Medicine report asserted that access-related factors are likely to be the most significant barriers to equitable health care for all populations and needs to be addressed as an important first step toward eliminating healthcare disparities (Institute of Medicine, n.d.). Accessing health care involves different levels such as: access to health information, access to physicians or to hospitals and clinics. Consumers need information to choose appropriate providers, sources of information, to follow treatment regimens, and to engage in more mutual decision making. Yet, some populations with the greatest needs have the least access to information.

Asians have greater difficulty in comprehending health-related information compared to other racial/ethnic groups. Asians (58\%) have a harder time understanding physician provided health information than Whites (41\%). Whereas, access to health care information from the World Wide Web, printed materials or obtaining it from 
calling physicians show no racial/ethnic differences (National Health Care Disparities Report, 2003; Williams \& Parker, 1995).

Another important barrier to health care access is language, leading to complications, especially among those receiving care in outpatient settings (Gandhi et al., 2000). Asian American and Pacific Islanders (AAPI) have a higher rate of hospital acquired infections (National Health Care Disparities Report, 2003), a greater representation of uninsured patients who suffer negligent medical injury in hospitals (Burstin, Lipsitz, \& Brennan, 1992), and more dissatisfaction $(28 \%)$ with overall care, than Whites $(16 \%)$. Reasons for low satisfaction include under-involvement in the decision making process, lack of ongoing source of care, and inability to get appointments for desired routine care (National Health Care Disparities Report, 2003).

\section{Utilization of Interpreters}

Patient centered research on quality of care has often excluded patients who speak little or no English (Frayne, Burns, Hardt, Rosen, \& Moskowitz, 1996). AAPI immigrants who speak limited or no English may encounter more barriers to quality care than the larger population. For example, $27 \%$ of AAPI reported poor communication with their health care providers during their most recent encounter, compared to $17 \%$ of Whites (National Health Care Disparities Report, 2003). According to the 1990 Census, nearly $14 \%$ of the population of the US speaks a language in their homes other than English. Language concordant patients have better health- related quality of life (PerezStable, Napoles-Springer, \& Miramontes, 1997). Many physicians rely on limited foreign language skills or on untrained interpreters (Baker, Parker, Williams, Coates, \& Pitkin, 1996). Physician-patient communication without an interpreter is recognized as a major challenge to effective health care delivery (Erzinger, 1991; Perez-Stable et al., 1997; Seijo, 1991).

Physician use of trained interpreters leads to higher quality of patient-physician communication than use of untrained staff or family members (Baker, Hayes, \& Fortier, 1998;
Baker, Parker, Williams, Coates, \& Pitkin, 1996). For example, Chinese and Vietnamese communities prefer trained interpreters to family members or ad hoc bilingual personnel; did not want to use children as interpreters and valued having same sex interpreters when dealing with sensitive issues, due to awareness of censorship by the interpreter (Ngo-Metzger et al., 2003).

Health professionals commonly use any available bilingual person when communicating with patients with limited English proficiency. Most ad hoc interpreters are family members and friends of the patient. Persons in the waiting room or staff from nearby ethnic restaurants also are used (Baker et al., 1996; Ginsberg, Martin, Andrulis, Shaw-Taylor, \& McGregor, 1995). Health care institutions vary in practice in maintaining formal and informal lists of bilingual staff and community members willing to volunteer as interpreters (Ginsberg, Martin, Andrulis, Shaw-Taylor, \& McGregor, 1995), having a group of interpreters who also serve as cultural mediators (Community House Calls, 2007), and use of professional interpreters with unlimited availability (Villarruel, Portillo, \& Kane, 1999). More research is necessary on utilization rates of types of interpreters and which are most efficient and effective.

\section{Cancer Screening}

Cancer is the number one cause of death among AAPI women (Chen \& Koh, 1997). However, they have the lowest screening rates of all ethnic groups in the US (American Cancer Society, 2004), and have a more aggressive type (Menon, Teh, \& Chua, 1992). Southeast Asian women present much later and have the highest mortality rate of all ethnic groups for cervical cancer (Miller et al., 1996). Only 68.2\% of AAPI women over the age of 18 years have had a Pap test within the past three years compared to White women $(83.9 \%$ ) (American Cancer Society, 2004), and $21 \%$ of the AAPI women have never had a Pap test, compared to only 5\% of the White women (Kagawa-Singer \& Pourat, 2000). These figures are far below the Healthy People 2010 guidelines, which recommend that $97 \%$ of women $\geq 18$ should receive a Pap test. 
The disparity exists for mammograms too. Among White women $\geq 40$ years, $72.1 \%$ have received a mammogram within the past 2 years and $56.9 \%$ of them have taken it within the last year. Whereas, among Asian American women $\geq 40$ years, only $57 \%$ of the population have had screening within the past two years and $47.8 \%$ of them in the last year (American Cancer Society, 2004). Despite the Healthy People 2010 recommendation that $70 \%$ of all women of age $>$ 40 years should be screened at least once within two years, many AAPI women $(30 \%)$ have never had a mammogram compared to White women (21\%) (Goel et al., 2003; Chen, Diamant, Kagawa-Singer et al., 2004; KagawaSinger \& Pourat, 2000).

Colon and prostate cancer rates vary among racial groups (American Cancer Society, 2004). Among Whites $\geq 50$ years, $18.3 \%$ have had a Fecal Occult Blood Test (FOBT) within the past year and an Endoscopy rate of $31.3 \%$ within the last five years, in contrast with $14.5 \%$ and $19.2 \%$ for Asians, respectively. Prostate cancer rates are the highest among African Americans and lowest among Asians as a whole.

The purpose of this study was to examine Asian subgroup differences in sources of health information and cancer screening, compare Asians and Whites in screening, and to examine the association between health information and screening behavior.

\section{Methods}

\section{Overview}

A 96-item questionnaire, developed by the Commonwealth Fund in collaboration with Princeton Survey Research Association was used. A nationally representative sample of 6,722 adults age 18 and older living in the continental United States who spoke English, Mandarin or Cantonese, Vietnamese or Korean was selected. The current sample for the study included 579 Asians and 3669 Whites. The survey was administered from April to November 2001 and took about 25 minutes to complete. The sample consisted of White, African-American, Hispanic and Asian households (Collins et al., 2002).

\section{Sample}

The sample was designed to generalize to the U. S. adult population (Collins et al., 2002). A stratified minority sample design was conducted, utilizing a random-digit dialing method. Telephone numbers were drawn disproportionately from area code exchange combinations with higher than average densities of minority households. Asians consisted of Chinese, Vietnamese, Koreans, Japanese, Filipino, Indian, Laotian, and others selfreported as Asians.

\section{Design}

The pretest of the questionnaire was completed based on a random digit phone sample of respondents. The final questionnaire was translated into multiple languages: Mandarin, Cantonese, Vietnamese and Korean. Up to 20 attempts were made to contact a person at every sampled telephone number. Telephone calls took place at various times of the day and days of the week to maximize the chance of making contact with potential participants. Interviewers randomly selected household members.

Five stages of statistical weighting were employed to assure a racial/ethnic distribution of a disproportionately large sample of Asian Americans, matching the distribution of the U.S. general adult population (Collins et al., 2002). The overall response rate was $54.3 \%$ which was based on the contact, cooperation (initial consent obtained), and completion (initially cooperating and eligible participants) rates.

\section{Instrument}

Questionnaire items included demographic variables, health status, cancer screening, health care experiences, health information sources, and use of an interpreter in the patient-provider interaction. Demographic variables included age, gender, English use as primary language spoken at home, employment of participant and spouse (full time, part time, unemployed), education level ( $<$ high school, high school, college/graduate, post graduate), income, US as country of origin, and length of time in the US $(<5$ years, $>5$ years $)$. 


\section{Sources of Health Information and Interaction with Healthcare Provider}

To determine source of health information, participants reported how often they acquire information from the World Wide Web, books or printed material, health care provider, friends or family, the pharmacist, or a community health fair. The ease (very easy, somewhat easy, not too easy, not at all easy, don't look for quality) of acquiring information about quality of physicians in the community, health insurance plans, and hospitals in the community was assessed. Difficulty reading instructions on prescription bottles, and information in booklets were measured (very easy, somewhat easy, not too easy, not at all easy, don't get any information from physician). Perceptions of health status after going to the hospital or health care provider, difficulty communicating with a healthcare provider (always, usually, sometimes, never) and need for an interpreter, preference for a healthcare provider from one's own ethnic/racial group, who serves as the interpreter (health care provider, staff person, friend or relative, trained medical interpreter, or someone else), and the interpreter's usual availability were included.

\section{Screening}

Participants reported previous cancer screening (pap test, mammogram, colon, prostate) for relevant cancers ( $<$ than a year ago, 1-2 years, 35 years, more than 5 years ago, or never). Analysis for the complete physical exam included the entire sample, the pap test included all women, mammograms included women 40 and over, colon screening included those age 50 and over, and for prostate cancer men 40 and older. The represented Asian subgroups $(\mathrm{N}=561)$ in Appendix A included Chinese, Vietnamese, Korean, Filipino, Indian, and Japanese. The represented Asian subgroups $(\mathrm{N}=574)$ in Appendix B included the six subgroups in Appendix A and some from the other category (e.g., Laotians, others self-reported as Asian).

\section{Statistical Analysis}

Descriptive statistics were reported for the variables that characterized Asian and nonAsians (SPSS 10.0). Due to disproportionate sampling, cases with no responses, and to more adequately reflect the US adult population, data were weighted. Chi-square analyses were conducted to examine the bivariate relationship between the dependent variable of ethnic subgroup (Chinese, Vietnamese, Korean, Filipino, Indian, and Japanese) and the independent variables. The independent variables were sex, age, language spoken at home, participant and spouse employment, education level, income, US as country of origin, length of time in the US, need for an interpreter with healthcare provider, availability of interpreter, and preference for having physicians from own race/ethnicity, and frequency of screening (physical exam, pap test, mammogram, colon cancer, and prostate cancer) by ethnic/racial subgroup and between Asians and Whites.

A one-way analysis of variance (ANOVA) was used to determine differences in means for age, health information source, information for quality of doctors, insurance plans, and hospitals in the community, difficulty reading/ understanding prescription labels and booklets, frequency of interpreters, understanding a physician with interpreter, and screening for cancers. Five separate logistic regression analyses were used in the present study to identify potential predictor variables of screening tests. The independent variables were health information source (from World Wide Web, books or printed material, a doctor or health care provider, asked friends or family, asked a pharmacist, from a community health fair), and ease to find information about the quality of: doctors in the community, health insurance plans, and hospitals in the community, and race (Whites, Asians). The dependent variables were screenings in the last two years for: a physical exam, colon cancer, prostate cancer, pap test, and mammogram. A forward stepwise selection of variables was used to select variables for inclusion in the final model. The criterion for entry of variables was .10 for each step and the significance criterion for selection of whether the variable remained was .05 . Whites and Asians were combined in the analysis with Whites serving as the reference category so that race could be a predictor variable. 


\section{Results}

\section{Characteristics of the Sample}

There was a significant difference between ethnic subgroups in mean age, gender, language spoken at home, employment, spouse employment, education, income, country of origin, and length of time in the US (Appendix C). Responses to this item were based on those whose primary language is not English or who took the survey in Mandarin, Cantonese, Korean, or Vietnamese and did not include Filipinos, Indians, Japanese, or others. A Tukey HSD test showed that Japanese $(\mathrm{M}=46.0$, $\mathrm{SD}=18.9$ ) were significantly older than Vietnamese, Korean, and Indian. Filipinos were significantly older than Indians. English was more likely to be spoken in Korean $(5.3 \%)$ homes than in Chinese and Vietnamese homes. Koreans $(5.3 \%)$ were more likely to speak English at home than Chinese (4.7\%) and Vietnamese (0\%). Among Asians who did not speak English as their primary language at home, Mandarin or Chinese $(51.3 \%)$, Korean $(22.5 \%)$, and Vietnamese $(21.3 \%)$ were spoken. Indians $(45.2 \%)$ were more likely to have a post graduate or professional education followed by Chinese $(33.3 \%)$, Japanese $(17.3 \%)$, Korean $(16.0 \%)$, Filipino (13.1\%), and Vietnamese $(3.8 \%)$. Indians were most likely to have a higher income and to have lived in the US longer than other Asian subgroups, while Chinese earned the least and Vietnamese lived in the US the shortest length of time.

\section{Sources of Health Information}

As shown in Appendix D, there were significant differences between ethnic subgroups in use of the World Wide Web, books or printed material, healthcare providers, and pharmacists as sources of health information. Overall, among Asians the World Wide Web, healthcare providers, pharmacists and health fairs were used "not too often" and books or printed material and friends or family were used somewhat often. A Tukey HSD test showed that Indians $(\mathrm{M}=2.7)$ were significantly more likely to use the World Wide Web than Chinese, Koreans, and Filipinos. Koreans $(\mathrm{M}=2.9, \mathrm{SD}=0.99)$ were significantly less likely to use printed materials than Filipinos and Japanese. Chinese $(\mathrm{M}=3.3, \mathrm{SD}=0.80)$ were significantly less likely to use healthcare providers than Indians and Japanese. Indians $(\mathrm{M}=2.9, \mathrm{SD}=0.92)$ were the most likely to ask pharmacists for health information and Vietnamese and Chinese were the least likely.

There were also significant differences between subgroups in ease of finding information about the quality of doctors, health insurance plans, and hospitals in the community. A Tukey HSD test indicated that Filipinos $(\mathrm{M}=2.0, \mathrm{SD}=0.86)$ were significantly more likely to be able to find information about quality of doctors than Chinese and Koreans. Indians $(\mathrm{M}=2.3, \mathrm{SD}=1.1)$ were significantly more likely to be able to find information about quality of doctors than Koreans. Koreans $(\mathrm{M}=2.8, \quad \mathrm{SD}=0.82)$ were significantly less likely to find information about quality of health insurance plans than Filipinos and Japanese. Filipinos $(\mathrm{M}=1.9, \mathrm{SD}=0.85)$ found it easier to obtain information about quality of hospitals in the community than Chinese, Vietnamese, and Koreans; Koreans found it harder than Indians and Japanese. Overall, Asians perceived it was easy $(\mathrm{M}=1.5, \mathrm{SD}=0.81)$ to read or understand instructions on a prescription bottle and information booklets in a physician's office. A Tukey test indicated that Chinese $(\mathrm{M}=1.6, \mathrm{SD}=0.9)$ were significantly less likely to be able to read or understand instructions on a prescription bottle than Filipinos; and Indians could more easily read or understand physician information booklets than Chinese, Vietnamese, and Koreans, and Filipinos could more easily read or understand information booklets than Koreans.

\section{Preference for and Communication with Physicians}

Overall, approximately $16.3 \%$ of Asians preferred to be treated by a racially concordant physician and there were significant differences between subgroups in this preference. Koreans $(32.0 \%)$ were the most likely to prefer having a physician of their own race/ethnicity and Indians $(6.5 \%)$ were the least preferential. In general, Asians $(\mathrm{M}=3.3, \mathrm{SD}=0.89)$ indicated that they sometimes have difficulty speaking with a physician and there were significant differences across ethnic subgroups. A Tukey test indicated that Koreans $(\mathrm{M}=3.6, \quad \mathrm{SD}=0.86)$ were significantly more likely to have difficulty 
speaking with a physician than Chinese and Vietnamese.

Asians $(\mathrm{M}=2.5, \quad \mathrm{SD}=0.97)$ usually use an interpreter. There were no significant differences between the ethnic subgroups in frequency of use and in who serves as an interpreter. For Chinese, Vietnamese, and Koreans, friends or relatives $(66.7 \%)$ are the most likely people to serve as interpreters followed by a staff person $(33.3 \%)$. Vietnamese indicated that friends and family were the only people to serve as interpreters. Responses to the items for use of interpreters were based on those who needed or used an interpreter and did not include Filipinos, Indians, Japanese, or others.

\section{Screening}

There were significant differences between subgroups in getting a complete physical exam and pap test (Appendix A). There were no significant subgroup differences reported in getting mammograms, colon cancer screening, and prostate cancer screening. Vietnamese $(17.0 \%)$ were more likely to have never been given a complete physical exam and Filipinos $(2.5 \%)$ were the least likely to never have had a physical exam. Overall, $71 \%$ of Asians had a physical within the last two years. Filipinos $(76.8 \%)$ were the most likely to have reported being given a physical within the last two years and Japanese $(46.1 \%)$ were the least likely. Among women, $76.4 \%$ went for a pap test within the last two years. Filipino women $(84.9 \%)$ were the most likely to be screened within the last two years and Korean women $(50.0 \%)$ were the least likely to be screened for cervical cancer within the last year.

There were significant differences between Whites and Asians in getting a complete physical exam and a pap test (Appendix B). Asians were less likely to ever have had a complete physical exam and pap tests than Whites and to have had one within the last two years.

The final logistical regression models for screenings is presented in Appendix E. Getting health information from the World Wide Web was positively correlated with getting a pap test.
Obtaining health information from books or other printed materials was positively correlated with screenings for a physical exam, colon cancer, and mammogram. Health information from a community health fair was significantly positively associated with getting a physical exam. Health information from a health care provider was positively associated with colon cancer screening and information from a pharmacist with prostate cancer screening. Obtaining health information from friends or family was positively correlated with getting a pap test. Ease of finding information about quality doctors in the community was positively associated with getting a physical exam, colon cancer screening, and a mammogram. The odds of getting a screening test based on the independent variables ranged from 1.28 to 2.12.

\section{Discussion}

\section{Health Information Sources}

This study found that Asian subgroups differentially used the World Wide Web (WWW), printed materials or books, healthcare providers, and pharmacists as sources of health information. While previous studies (National Health Care Disparities Report, 2003) showed no differential use between ethnic/racial groups for sources of health information, this study found Asian subgroup differences. Asians were more likely to use printed materials or friends or family as their source of health information. The WWW may be a useful source to influence health behaviors among this population, especially if the information can be tailored to Asian subgroups. Differences between Asian subgroups in use of these sources of health information implies that interventions to improve screening and health status should consider which source is most used by the particular subgroup. In addition, some of the sources may not be as effective due to a lack of information at that source or due to a lack of information in their native language. For example, while Indians reported significantly more use of the WWW than other Asian subgroups, making the WWW a potentially good source of health information for that population, these differences may reflect a more facile use of English which makes the WWW a more useful source of health information available to 
Indians. If other Asian subgroups have more difficulty with English, then they will need access to health information in their native language.

The fact that certain Asian subgroups were less likely to consult with a health care provider or a pharmacist than other Asian groups may indicate a tendency to seek out information prior to approaching a health care provider, or they may find difficulty approaching health care providers (Saha et al., 2003). For example, Chinese were less likely to use healthcare providers as a source of health information than Indians and Japanese, two groups that culturally have been more exposed to English speaking influence. Some Asian subgroups found it more difficult to read or understand information on prescription bottles and in booklets in physician offices than other subgroups (National Health Care Disparities Report, 2003). For example, Koreans were less likely to use printed materials than Filipinos and Japanese. Chinese were less likely to be able to read or understand instructions on a prescription bottle than Filipinos, and Indians more easily read or understood them than Chinese, Vietnamese, and Koreans; and Filipinos more than Koreans. These data indicated that in general, Filipinos and Japanese seem to have an easier time getting health information than other Asian subgroups. One explanation may be that these cultures have been more culturally influenced by English speakers and they more easily can obtain health information due to language and cultural facility (Gandhi et al., 2000).

Linguistic and cultural facility may also explain why there were also differences in ethnic subgroups in ease of finding information about physician quality, health insurance plans, and hospitals in the community. Filipinos were more easily able to obtain information about quality of physicians than Chinese or Koreans; and Indians more than Koreans. Filipinos and Japanese were more able to obtain information about health insurance plans than Koreans. Further, Filipinos were able to more easily find information about hospitals than Chinese, Vietnamese, and Koreans and Indians and Japanese found it easier than Koreans.

\section{Communication with Physicians}

Asian subgroups differed in preference to be treated by a racially concordant health care provider. Koreans (32.0\%) preferred concordance the most, followed by Vietnamese (24.5\%), Chinese (21.2\%), Filipino (9.8\%), Japanese (7.7\%), and Indians (6.5\%). Since previous literature indicates that language concordant patients have better health-related quality of life (Perez-Stable et al., 1997), these subgroup differences indicate an opportunity to enhance healthcare delivery for specific Asian subgroups who need racially concordant service provision. Among those who had difficulty speaking with a physician, the Asian subgroups usually used an interpreter and there were no differences in use of an interpreter between these groups. Two-thirds of Chinese, Vietnamese, and Koreans used family and friends as interpreters and one-third used staff persons at the health care facility. Vietnamese reported only using family and friends. They also indicated that these interpreters are not always available. Use of friends and family members is problematic because untrained interpreters often lead to less quality of patient-provider communication (Baker et al., 1996; Baker et al., 1998). This study shows that since family members are most often used as interpreters and if these tend to be less available and less accurate than trained interpreters, health care providers should be cautious about using just any available bilingual person, especially children (Ngo-Metzger et al., 2003). Use of family and friends also does not provide for privacy and confidentiality that is often desired in communicating with a health care provider.

\section{Screening}

The groups varied in getting a complete physical exam and Pap test. Vietnamese were more likely to have never had a complete physical exam and Filipinos the least likely. Yet, overall, $71 \%$ of Asians had a physical within the last two years. Filipinos $(76.8 \%)$ were the most likely to have reported being given a physical within the last two years and Japanese (46.1\%) were the least likely. Since cancer and other specific screening tests such as diabetes and high blood pressure are often performed in the context of a routine physical exam, it is important to know physical 
exam rates and the factors that influence these rates. While future study could examine the link between getting a physical and getting other screening tests, this study found a positive relationship between getting a general physical exam, and obtaining health information from books/printed materials, a community health fair, and easily finding information about quality doctors in the community. Previous studies have estimated that $68.2 \%$ of AAPI women over 18 years of age have had a Pap test within the last three years (Cancer facts and figures, 2004), and $21 \%$ of never had a Pap test compared to only $5 \%$ of White women (Kagawa-Singer, \& Pourat, 2000). Consistent with these previous studies, the current study found that overall, $23.6 \%$ of Asians did not go within the last three years and 10.7 never went for a Pap test. The current study also found that the number of women in the subgroups who did not get a Pap screening within the last three years ranged from $15.1 \%$ for Filipinos to $50 \%$ for Koreans. The subgroup differences in never getting Pap tests ranged from $5.5 \%$ among Filipinos to $15.0 \%$ in Vietnamese. These subgroup differences indicate the need to specifically target certain Asian subgroups to increase knowledge, and change attitudes and behaviors with regard to the need for cervical cancer screening. The current study also found that the number of Asians in the subgroups who did not get a general physical within the last three years ranged from $21.7 \%$ for Indians to $52 \%$ for Koreans. The subgroup differences in never getting a physical ranged from 2.5\% among Filipinos to $17.0 \%$ in Vietnamese. These subgroup differences indicate the need to specifically target certain Asian subgroups to increase knowledge, and change attitudes and behaviors with regard to the need for getting a routine physical in general and cervical cancer screening in particular. While there were no significant differences between subgroups in mammograms, colon cancer screening, and prostate cancer screening, the percentages of those who have never gone for one are high. While cancer is the leading cause of death for Asians, they have the lowest screening rates (American Cancer Society, 2004; Chen \& Koh, 1997). This may reflect AAPI attitudes about fatalism toward health. Ill health is associated with misfortune or external forces over which they have no control (Chin \& Bigby, 2003; Rasbridge, n.d.). Demographic factors such as a higher education level, having medical insurance, and those who live in the US 10+ years increase the likelihood for screening (American Cancer Society, 2004). However, this was not the case for Asian American women. It is presumed other cultural or social factors attribute to this disparity.

In comparing Asians with Whites on screening, Whites were significantly more likely to have had a general physical exam and a Pap test than Asians. While no significant differences were found between Asians and Whites in getting mammograms, screening for colon and prostate cancers, Asians were less likely to have been screened than Whites for all these tests.

While other studies (National Health Care Disparities Report, 2003; Williams \& Parker, 1995) did not find racial/ethnic differences in access to health care information from the World Wide Web, printed materials, and by getting information from calling physicians, this study found that there were differences in sources of health information and their association with particular screening behaviors. Future research could determine the impact on screening behavior by using particular sources of information. Also, while previous studies (National Health Care Disparities Report, 2003; Williams \& Parker, 1995) have found that Asians have a harder time understanding healthrelated information than Whites, this study found that sources of health information are associated with particular screening behaviors. More effort will be needed in identifying how each source of information may differentially promote screening for particular cancers or getting a physical exam. Further, it should not be assumed that older individuals will be less likely to get information from certain sources such as the World Wide Web. While older individuals may not be accustomed to using a computer, younger generations can provide this information, as they do interpretation (Baker et al., 1998; Baker et al., 1996).

The study had the following limitations. First, it was a cross-sectional study and therefore it is 
not possible to determine causality. For example, having access to certain sources of health information may be associated with increased probability of screening, but it is difficult to ascertain whether access to health sources will lead to improved screening rates. Second, while the overall response rate of $54.3 \%$ is less than desirable, it is useful given the difficulty of surveying the Asian populations. Asians are reluctant to share personal information with researchers.

The findings in this study indicate differences in sources of health information between Asian subgroups, that Asians used family and friends as interpreters for health care services and that various sources of health information may differentially be related to obtaining particular screenings. These findings suggest that as a prelude to accessing health care services, consideration should be given to developing sources of health information relevant to specific Asian subgroups so as to enhance their decision making prior to and in conjunction with receiving medical care services. Informed decisions as health care consumers will more likely reduce the health and cancer disparity that exists between ethnic/racial groups and subgroups.

\section{References}

American Cancer Society. (2004). Cancer facts and figures, 2003. Cancer Fact Sheet. Atlanta: Author.

Baker, D. W., Hayes, R., \& Fortier, J. P. (1998). Interpreter use and satisfaction with interpersonal aspects of care for Spanish speaking patients. Medical Care, 36, 1461-1470.

Baker, D. W., Parker, R. M., Williams, M. V., Coates, W. C., \& Pitkin, K. (1996). Use and effectiveness of interpreters in an emergency department. Journal of the American Medical Association, 275, 783-788.

Burstin, H. R., Lipsitz, S. R., \& Brennan, T. A. (1992). Socioeconomic status and risk for substandard medical care. Journal of the American Medical Association, 268, 2383-2387.

Chen, J. Y., Diamant, A. L., Kagawa-Singer, M., Pourat, N., \& Wold, C. (2004). Disaggregating data on Asian and Pacific Islander women to assess cancer screening. American Journal of Preventive Medicine, 27, 139-145.

Chen, M. S., \& Koh, H. K. (1997). The need for cancer prevention and control among Asian American and Pacific Islanders. Asian American Pacific Islander Journal of Health, 5, 3-6.

Chin, J. L., \& Bigby, J. (2003). Care of Asian Americans. In J. Bigby, Cross-cultural medicine. Philadelphia: American College of Physicians.

Collins, K. S., Hughes, D. L., Doty, M. M., Ives, B. L., Edwards, J. N., \& Tenney, K. (2002). Diverse communities common concerns: Assessing the Health Quality for Minority Americans. New York: The Commonwealth Fund.

Community House Calls. (2007). Community House Calls programs. Retrieved July 1, 2007, from http://ethnomed.org/ethnomed/chc/chc.html

Erzinger, S. (1991). Communication between Spanish-speaking patients and their doctors in medical encounters. Culture, Medicine and Psychiatry, 15, 91.

Frayne, S. M., Burns, R. B., Hardt, E. J., Rosen, A. K., \& Moskowitz, M. A. (1996). The general exclusion of non-English-speaking persons from research. Journal of General Internal Medicine, $11,39-43$.

Gandhi, T. K., Burstin, H. R., Cook, E. F., Puopolo, A. L., Haas, J. S., Brennan, T. A., \& Bates, D. W. (2000). Drug complications in outpatients. Journal of General Internal Medicine, 15, 149-154.

Ginsberg, C., Martin, V., Andrulis, D., Shaw-Taylor, Y., \& McGregor, C. (1995). Interpretation and translation services in health care: a survey of US public and private teaching hospitals. A National Public Health and Hospitals Institute (NPPHI) Report. Washington (DC).

Goel, S. M., Wee, C. C., McCarthy, E. P., Davis, R. B., Ngo-Metzger, Q., \& Phillips, R. S. (2003). Racial and ethnic disparities in cancer screening: the importance of foreign birth to care. Journal of General Internal Medicine, 18, 1028-1035. 
Haviland, M. G., Morales, L. S., Reise, S. P., \& Hays, R. D. (2003). Do health care ratings differ by race or ethnicity? Joint Commission Journal on Quality and Safety, 29, 134-45.

Institute of Medicine. (n.d.). Unequal treatment: Confronting racial and ethnic disparities in healthcare. Retrieved November 20, 2003, from http://www.iom.edu/report.asp?id=4475

Kagawa-Singer, M., \& Pourat, N. (2000). Asian American and Pacific Islander breast and cervical carcinoma screening rates and Healthy People 2000 objectives. Cancer, 89, 696-705.

Menon, M., The, C. H., \& Chua, C. L. (1992). Clinical and social problems in young women with breast carcinoma. Australian and New Zealand Journal of Surgery, 62, 364-367.

Miller, B. A., Kolonel, L. N., Bernstein, L., Young, J. L., Swanson, G. M., West, D.W., Key, C. R., Liff, J. M., Glover, C. S., \& Alexander, G. A. (1996). Racial/ethnic patterns of cancer in United States 1988-1992. National Cancer Institute, NIH Pub. No. 96-4104. Bethesda, MD.

National Health Care Disparities Report. (2003). Agency for Healthcare Research and Quality (AHRQ), U.S. Department of Health and Human Services. Retrieved November 20, 2003, from http://www.qualitytools.ahrq.gov/disparitiesreport/download report.aspx

Ngo-Metzger, Q., Massagli, M.P., Clarridge, B. R., Manocchia, M., Davis, R. B., Lezzoni, L. I., \& Phillips, R. S. (2003). Linguistic and cultural barriers to care: Perspectives of Chinese and Vietnamese immigrants. Journal of General Internal Medicine, 18, 44-52.

Perez-Stable, E. J., Napoles-Springer, A., \& Miramontes, J. M. (1997). The effect of ethnicity and language on medical outcomes of patients with hypertension or diabetes. Medical Care, 35, 12121219.

Rasbridge, L. A. (n.d.). Vietnamese-American profile: Asian-American health. Retrieved July 21, 2003, from http://www3.baylor.edu/ Charles Kemp/vietnamese health.htm

Saha, S., \& Hickam, D. H. (2003). Explaining low ratings of patient satisfaction among Asian-Americans. American Journal of Medical Quality, 18, 256-64.

Saha, S., Arbelaez, J. J., \& Cooper, L. A. (2003). Patient-physician relationships and racial disparities in the quality of health care. American Journal of Public Health, 93, 1713-1719.

Seijo, R. (1991). Language as a communication barrier in medical care for Latino patients. Hispanic Journal of Behavior Science, 13, 363.

Villarruel, A. M., Portillo, C. J., \& Kane, P. (1999). Communicating with limited English proficiency persons: Implications for nursing practice. Nursing Outlook, 47, 262-70.

Williams, M. V., \& Parker, R. M. (1995). Inadequate functional health literacy among patients at two public hospitals. Journal of the American Medical Association, 274, 1677-1682.

\section{Acknowledgments}

This publication was supported by NIH-National Cancer Institute's project "ATECAR - Community Cancer Network," at Center for Asian Health, College of Health Professions (Principal Investigator: Grace Ma, Ph.D.). The Center for Asian Health would also like to thank the Commonwealth Fund for access to data for use in this study. The authors are solely responsible for the contents of the study.

\section{Author Information}

Steven E. Shive, Ph.D., M.P.H.

Center for Asian Health

Temple University

And

Department of Health

East Stroudsburg University

DeNike Hall, 200 Prospect St.

East Stroudsburg University 
East Stroudsburg, PA 18301-2999

Ph.: 570-422-3330

Fax.: 570-422-3848

E-Mail: sshive@po-box.esu.edu

Grace X. Ma, Ph.D.

Yin Tan, M.D.

Jamil I. Toubbeh, Ph.D.

Lalitha Parameswaran, MD, MPH

Center for Asian Health

Department of Public Health

College of Health Professions

Temple University

Philadelphia, PA

Joseph Halowich, M.S., CHES

Health Faculty

Parkside High School

Salisbury, MD

* corresponding author 


\section{Appendix A}

\section{Screening Tests by Asian Subgroup}

\begin{tabular}{|c|c|c|c|c|c|c|c|c|}
\hline Screening Tests & $\begin{array}{c}\text { Total } \\
(\%)\end{array}$ & $\begin{array}{c}C \\
(\%)\end{array}$ & $\begin{array}{c}V \\
(\%)\end{array}$ & $\begin{array}{c}\mathrm{K} \\
(\%)\end{array}$ & $\begin{array}{c}F \\
(\%)\end{array}$ & $\begin{array}{c}\text { I } \\
(\%)\end{array}$ & $\begin{array}{c}\mathbf{J} \\
(\%)\end{array}$ & $\chi^{2}$ \\
\hline Complete physical exam & $\mathrm{N}=561$ & $\mathrm{~N}=189$ & $\mathrm{~N}=53$ & $\mathrm{~N}=50$ & $\mathrm{~N}=124$ & $\mathrm{~N}=93$ & $\mathrm{~N}=52$ & \\
\hline$<1$ year ago & 35.9 & 33.2 & 22.6 & 24.0 & 41.3 & 44.6 & 3.8 & \\
\hline $1-2$ years ago & 35.1 & 37.4 & 43.4 & 24.0 & 35.5 & 33.7 & 42.3 & \\
\hline $3-5$ years ago & 13.2 & 11.2 & 7.5 & 20.0 & 17.4 & 10.9 & 30.8 & \\
\hline$>5$ years ago & 8.6 & 10.2 & 9.4 & 20.0 & 3.3 & 5.4 & 13.5 & \\
\hline Never & 7.2 & 8.0 & 17.0 & 12.0 & 2.5 & 5.4 & 9.6 & $44.4^{* * * *}$ \\
\hline Colon cancer ${ }^{\mathrm{a}}$ & $\mathrm{N}=280$ & $\mathrm{~N}=97$ & $\mathrm{~N}=20$ & $\mathrm{~N}=22$ & $\mathrm{~N}=73$ & $\mathrm{~N}=41$ & $\mathrm{~N}=27$ & \\
\hline$<1$ year ago & 18.6 & 20.5 & 12.5 & 0 & 21.2 & 27.3 & 13.3 & \\
\hline $1-2$ years ago & 16.8 & 20.5 & 0 & 14.3 & 18.2 & 0 & 26.7 & \\
\hline $3-5$ years ago & 14.2 & 12.8 & 25.0 & 0 & 12.1 & 9.1 & 26.7 & \\
\hline$>5$ years ago & 3.5 & 0 & 0 & 0 & 3.0 & 18.2 & 6.7 & \\
\hline Never & 46.9 & 46.2 & 62.5 & 85.7 & 45.5 & 45.5 & 26.7 & 23.4 \\
\hline Prostate blood test or rectal examb & $\mathrm{N}=96$ & $\mathrm{~N}=26$ & $\mathrm{~N}=14$ & $\mathrm{~N}=9$ & $\mathrm{~N}=19$ & $\mathrm{~N}=14$ & $\mathrm{~N}=14$ & \\
\hline$<1$ year ago & 37.5 & 24.6 & 28.6 & 22.2 & 42.1 & 42.9 & 50.0 & \\
\hline $1-2$ years ago & 20.8 & 19.2 & 35.7 & 11.1 & 21.1 & 14.3 & 21.4 & \\
\hline $3-5$ years ago & 9.4 & 15.4 & 0 & 0 & 10.5 & 0 & 21.4 & \\
\hline$>5$ years ago & 5.2 & 0 & 7.1 & 22.2 & 5.3 & 7.1 & 0 & \\
\hline Never & 27.1 & 30.8 & 28.6 & 44.4 & 21.1 & 35.7 & 7.1 & 21.7 \\
\hline Pap test ${ }^{c}$ & $\mathrm{~N}=280$ & $\mathrm{~N}=97$ & $\mathrm{~N}=20$ & $\mathrm{~N}=22$ & $\mathrm{~N}=73$ & $\mathrm{~N}=41$ & $\mathrm{~N}=27$ & \\
\hline$<1$ year ago & 46.8 & 45.4 & 25.0 & 31.8 & 53.4 & 48.8 & 59.3 & \\
\hline $1-2$ years ago & 29.6 & 33.0 & 35.0 & 18.2 & 31.5 & 26.8 & 22.2 & \\
\hline $3-5$ years ago & 68.6 & 4.1 & 15.0 & 18.2 & 9.6 & 9.8 & 7.4 & \\
\hline$>5$ years ago & 4.3 & 3.1 & 10.0 & 18.2 & 0 & 2.4 & 7.4 & \\
\hline Never & 10.7 & 14.4 & 15.0 & 13.6 & 5.5 & 12.2 & 3.7 & $33.5^{*}$ \\
\hline Mammogram $^{\mathrm{d}}$ & $\mathrm{N}=136$ & $\mathrm{~N}=48$ & $\mathrm{~N}=7$ & $\mathrm{~N}=11$ & $\mathrm{~N}=46$ & $\mathrm{~N}=11$ & $\mathrm{~N}=13$ & \\
\hline$<1$ year ago & 40.4 & 43.8 & 14.3 & 45.5 & 45.7 & 36.4 & 23.1 & \\
\hline $1-2$ years ago & 33.1 & 41.7 & 42.9 & 9.1 & 21.7 & 54.5 & 38.5 & \\
\hline $3-5$ years ago & 5.1 & 2.1 & 0 & 18.2 & 4.3 & 0 & 15.4 & \\
\hline$>5$ years ago & 5.9 & 6.3 & 0 & 0 & 10.9 & 0 & 0 & \\
\hline Never & 15.4 & 6.3 & 42.8 & 17.3 & 17.4 & 9.1 & 23.1 & 29.8 \\
\hline
\end{tabular}

Note: $\mathrm{C}=$ Chinese, $\mathrm{V}=$ Vietnamese, $\mathrm{K}=$ Koreans, $\mathrm{F}=$ Filipino, $\mathrm{I}=$ Indian, $\mathrm{J}=$ Japanese

${ }^{*} \mathrm{p}<.05,{ }^{* *} \mathrm{p}<.001 ;{ }^{\mathrm{a}}$ Based on age $50+;{ }^{\mathrm{b}}$ Based on men $40+;{ }^{\mathrm{c}}$ Based on women only; ${ }^{\mathrm{d}}$ Based on women $40+$ 


\section{Appendix B}

\section{Screening Tests by Race/Ethnicity}

\begin{tabular}{|c|c|c|c|c|}
\hline Screening & Total (\%) & Asians (\%) & Whites (\%) & $\chi^{2}$ \\
\hline Complete physical exam & $\mathrm{N}=4196$ & $\mathrm{~N}=574$ & $\mathrm{~N}=3622$ & \\
\hline$<1$ year ago & 45.3 & 35.9 & 46.8 & \\
\hline $1-2$ years ago & 27.0 & 33.4 & 26.0 & \\
\hline $3-5$ years ago & 13.1 & 13.2 & 13.1 & \\
\hline$>5$ years ago & 10.7 & 8.7 & 11.1 & \\
\hline Never & 3.8 & 8.7 & 3.0 & $68.9^{* * *}$ \\
\hline Colon cancer $^{\mathrm{a}}$ & $\mathrm{N}=1482$ & $\mathrm{~N}=110$ & $\mathrm{~N}=1372$ & \\
\hline$<1$ year ago & 25.2 & 20.9 & 25.5 & \\
\hline $1-2$ years ago & 22.1 & 16.4 & 22.7 & \\
\hline $3-5$ years ago & 11.9 & 11.8 & 11.9 & \\
\hline$>5$ years ago & 6.6 & 5.5 & 6.7 & \\
\hline Never & 34.1 & 45.5 & 33.2 & 7.4 \\
\hline Prostate blood test or rectal exam ${ }^{b}$ & $\mathrm{~N}=867$ & $\mathrm{~N}=103$ & $\mathrm{~N}=764$ & \\
\hline$<1$ year ago & 46.3 & 38.8 & 47.3 & \\
\hline $1-2$ years ago & 21.5 & 21.4 & 21.5 & \\
\hline $3-5$ years ago & 9.2 & 8.7 & 9.3 & \\
\hline$>5$ years ago & 5.3 & 4.9 & 5.4 & \\
\hline Never & 17.8 & 26.2 & 16.6 & 6.2 \\
\hline Pap test ${ }^{\mathrm{c}}$ & $\mathrm{N}=2503$ & $\mathrm{~N}=277$ & $\mathrm{~N}=2226$ & \\
\hline$<1$ year ago & 55.2 & 46.6 & 56.2 & \\
\hline $1-2$ years ago & 26.1 & 29.7 & 25.7 & \\
\hline $3-5$ years ago & 7.8 & 9.0 & 7.6 & \\
\hline$>5$ years ago & 6.9 & 4.7 & 7.2 & \\
\hline Never & 4.1 & 10.5 & 3.3 & $39.5^{* * *}$ \\
\hline Mammogram $^{\mathrm{d}}$ & $\mathrm{N}=1486$ & $\mathrm{~N}=122$ & $\mathrm{~N}=1364$ & \\
\hline$<1$ year ago & 49.7 & 41.8 & 50.4 & \\
\hline $1-2$ years ago & 27.3 & 30.3 & 27.0 & \\
\hline $3-5$ years ago & 7.2 & 5.7 & 7.3 & \\
\hline$>5$ years ago & 5.6 & 5.7 & 5.6 & \\
\hline Never & 10.3 & 16.4 & 9.8 & 7.3 \\
\hline
\end{tabular}

Note: All Asians in the sample are represented including Chinese, Vietnamese, Koreans, Filipino,

Indian, Japanese, and others self-reported as Asians (e.g., Laotians, Persians)

*** $<<.001 ;{ }^{\mathrm{a}}$ Based on age $50+;{ }^{\mathrm{b}}$ Based on males $40+;{ }^{\mathrm{C}}$ Based on women only; ${ }^{\mathrm{d}}$ Based on women $40+$ 


\section{Appendix C}

\section{Characteristics of the Sample by Ethnic Subgroup}

\begin{tabular}{|c|c|c|c|c|c|c|c|c|}
\hline & $\begin{array}{c}\text { Total } \\
\mathrm{N}=561\end{array}$ & $\begin{array}{c}\mathrm{C} \\
\mathrm{N}=189\end{array}$ & $\begin{array}{c}\mathrm{V} \\
\mathrm{N}=53\end{array}$ & $\begin{array}{c}\mathrm{K} \\
\mathrm{N}=50\end{array}$ & $\begin{array}{c}\mathrm{F} \\
\mathrm{N}=124\end{array}$ & $\begin{array}{c}\mathrm{I} \\
\mathrm{N}=93\end{array}$ & $\begin{array}{c}J \\
N=52\end{array}$ & Stat \\
\hline Age(Mean, SD) & $39.9(16.2)$ & $40.7(17.8)$ & 36.3 & $36.5(13.5)$ & $42.2(15.2)$ & $35.9(14.3)$ & $46.0(18.9)$ & $\mathrm{F}=4.2^{* * *}$ \\
\hline $18-29$ & 28.7 & 29.5 & 34.0 & 32.0 & 21.1 & 37.4 & 20.0 & \\
\hline $30-39$ & 28.4 & 28.4 & 26.4 & 28.0 & 26.0 & 34.1 & 26.0 & \\
\hline $40-49$ & 21.6 & 19.7 & 24.5 & 26.0 & 25.2 & 16.5 & 22.0 & \\
\hline $50-64$ & 14.9 & 15.8 & 13.2 & 10.0 & 18.7 & 11.0 & 16.0 & $\chi^{2}$ \\
\hline $65+$ & 6.4 & 6.6 & 1.9 & 4.0 & 8.9 & 1.1 & 16.0 & 29.0 \\
\hline Female & 53.8 & 57.1 & 41.5 & 46.0 & 62.9 & 47.3 & 51.9 & $11.1^{*}$ \\
\hline \multicolumn{9}{|l|}{$\begin{array}{l}\text { Language spoken at } \\
\text { home }^{\mathrm{a}}\end{array}$} \\
\hline English & 3.6 & 4.7 & 0 & 5.3 & 0 & 0 & 0 & \\
\hline Mandarin/ Chinese & 51.3 & 93.0 & 5.6 & 0 & 0 & 0 & 0 & \\
\hline Korean & 22.5 & 0 & 0 & 94.7 & 0 & 0 & 0 & \\
\hline Vietnamese & 21.3 & 0 & 94.4 & 0 & 0 & 0 & 0 & \\
\hline Other & 1.3 & 2.3 & 0 & 0 & 0 & 0 & 0 & $149.8^{* * *}$ \\
\hline \multicolumn{9}{|l|}{ Employment } \\
\hline Full-Time & 58.1 & 57.5 & 47.2 & 54.0 & 62.1 & 65.6 & 51.9 & \\
\hline Part-Time & 1.8 & 1.6 & 11.3 & & & 1.1 & & \\
\hline Unemployed & 40.1 & 40.9 & 41.5 & 46.0 & 37.9 & 33.3 & 48.1 & $36.6^{* * *}$ \\
\hline \multicolumn{9}{|l|}{ Spouse Employment } \\
\hline Full-Time & 73.7 & 74.5 & 64.5 & 66.7 & 81.8 & 71.0 & 70.4 & \\
\hline Part-Time & 4.8 & 0.9 & 6.5 & & 6.5 & 11.3 & 3.7 & \\
\hline Unemployed & 21.6 & 24.5 & 29.0 & 33.3 & 11.7 & 17.7 & 25.9 & \\
\hline Student & 0 & 0 & 0 & 0 & 0 & 0 & 0 & $19.4^{*}$ \\
\hline \multicolumn{9}{|l|}{ Education } \\
\hline$<$ H.S. & 4.1 & 3.8 & 15.1 & 6.0 & 1.6 & 2.2 & 1.9 & \\
\hline High School & 11.0 & 11.3 & 15.1 & 12.0 & 9.8 & 8.6 & 11.5 & \\
\hline College/graduate & 59.9 & 51.6 & 66.0 & 66.0 & 75.4 & 44.1 & 69.2 & \\
\hline $\begin{array}{l}\text { Post grad/ } \\
\text { professional }\end{array}$ & 25.0 & 33.3 & 3.8 & 16.0 & 13.1 & 45.2 & 17.3 & $72.7^{* * * *}$ \\
\hline \multicolumn{9}{|l|}{ Income } \\
\hline$<20,000$ & 14.2 & 37.0 & 27.5 & 11.2 & 9.1 & 7.3 & 10.3 & \\
\hline $20 \mathrm{~K}-34,999$ & 13.3 & 13.0 & 7.5 & 17.8 & 6.5 & 12.2 & 15.5 & \\
\hline $35 \mathrm{~K}-49,999$ & 20.2 & 26.1 & 22.5 & 25.2 & 14.3 & 22.0 & 16.8 & \\
\hline $50 \mathrm{~K}-74,999$ & 18.7 & 8.7 & 20.0 & 17.8 & 24.7 & 14.6 & 20.0 & \\
\hline $75 \mathrm{~K}+$ & 33.7 & 15.2 & 22.5 & 28.0 & 45.5 & 43.9 & 37.4 & $54.1^{* * *}$ \\
\hline US country of origin & 21.6 & 25.7 & 7.7 & 12.0 & 18.7 & 7.6 & 61.5 & $70.8^{* * * *}$ \\
\hline \multicolumn{9}{|l|}{ Length of time in US } \\
\hline$<5$ years & 18.6 & 17.0 & 2.1 & 16.3 & 13.0 & 38.8 & 15.0 & \\
\hline$>5$ years & 81.4 & 83.0 & 97.9 & 83.7 & 87.0 & 61.2 & 85.0 & $34.3^{* * * *}$ \\
\hline
\end{tabular}

Note. $\mathrm{C}=$ Chinese, $\mathrm{V}=$ Vietnamese, $\mathrm{K}=$ Koreans, $\mathrm{F}=$ Filipino, $\mathrm{I}=$ Indian, $\mathrm{J}=$ Japanese

${ }^{\mathrm{a}}$ Based on those whose primary language is not English or who took the survey in Mandarin, Cantonese, Korean, or Vietnamese. $* \mathrm{p}<.05, * * \mathrm{p}<.01 ; * * \mathrm{p}<.001$ 


\section{Appendix D}

\section{Source of Health Information by Asian Subgroup}

\begin{tabular}{|c|c|c|c|c|c|c|c|c|}
\hline & $\begin{array}{c}\text { Total } \\
\mathbf{N}=561\end{array}$ & $\begin{array}{c}C \\
N=189\end{array}$ & $\begin{array}{c}V \\
N=53\end{array}$ & $\begin{array}{c}K \\
N=50\end{array}$ & $\begin{array}{c}\mathrm{F} \\
\mathrm{N}=124\end{array}$ & $\underset{N=93}{I}$ & $\begin{array}{c}J \\
N=52\end{array}$ & Stat \\
\hline Health information source $^{\mathrm{a}}$ & & & & & & & & $\mathbf{F}$ \\
\hline From World Wide Web & $3.0(1.1)$ & $3.1(.9)$ & $3.2(1.1)$ & $3.2(.96)$ & $3.2(1.0)$ & $2.7(1.2)$ & $2.8(1.2)$ & $3.9 * *$ \\
\hline $\begin{array}{l}\text { Books or other printed } \\
\text { material }\end{array}$ & $2.5(1.0)$ & $2.5(.9)$ & $2.8(1.1)$ & $2.9(.99)$ & $2.4(.99)$ & $2.5(1.1)$ & $2.3(1.0)$ & $3.60 * *$ \\
\hline $\begin{array}{l}\text { Called Doctor/other HC } \\
\text { provider }\end{array}$ & $3.1(.91)$ & $3.3(.8)$ & $3.3(.91)$ & $3.3(.90)$ & $3.0(.94)$ & $2.9(.96)$ & $2.8(.93)$ & $5.10 * * *$ \\
\hline Asked friends or family & $2.7(1.0)$ & $2.8(.9)$ & $2.9(1.1)$ & $2.8(.82)$ & $2.6(1.1)$ & $7.7(1.1)$ & $2.4(.94)$ & 1.50 \\
\hline Asked Pharmacist & $3.2(.91)$ & $3.3(.8)$ & $3.2(.99)$ & $3.4(.69)$ & $3.0(1.0)$ & $3.2(.89)$ & $2.9(.92)$ & $2.40^{*}$ \\
\hline From Community Health Fair & $3.6(.65)$ & $3.6(.7)$ & $3.7(.59)$ & $3.8(.46)$ & $3.6(.73)$ & $3.7(.59)$ & $3.6(.67)$ & 0.90 \\
\hline \multicolumn{9}{|l|}{$\begin{array}{l}\text { Ease to find information about the } \\
\text { quality of: }{ }^{b}\end{array}$} \\
\hline Doctors in community & $2.3(.96)$ & $2.5(.9)$ & $2.3(.97)$ & $2.8(.95)$ & $2.0(.86)$ & $2.3(1.1)$ & $2.3(1.0)$ & $5.50 * * *$ \\
\hline Health insurance plans & $2.4(.95)$ & $2.4(.9)$ & $2.4(.92)$ & $2.8(.82)$ & $2.2(.93)$ & $2.3(1.1)$ & $2.2(1.1)$ & $2.80^{*}$ \\
\hline Hospitals in community & $2.2(.96)$ & $2.3(.9)$ & $2.5(1.0)$ & $2.7(.92)$ & $1.9(.85)$ & $2.1(.98)$ & $2.1(.97)$ & $6.00 * * *$ \\
\hline $\begin{array}{l}\text { Difficulty reading/understanding } \\
\text { instructions on prescription } \\
\text { bottle }^{c}\end{array}$ & $1.5(.81)$ & $1.6(.9)$ & $1.6(.84)$ & $1.7(.92)$ & $1.3(.73)$ & $1.4(.74)$ & $1.3(.58)$ & $3.80 * *$ \\
\hline $\begin{array}{l}\text { Difficulty reading/understanding } \\
\text { information/booklets at Dr's } \\
\text { office }^{c}\end{array}$ & $1.8(.97)$ & $1.9(.9)$ & $1.9(.99)$ & $2.2(1.0)$ & $1.7(.93)$ & $1.5(.91)$ & $1.7(.95)$ & $5.70 * * *$ \\
\hline & & & & & & & & $\chi^{2}$ \\
\hline \multicolumn{9}{|l|}{ Preference of Physician(\%) } \\
\hline Own race/ethnicity & 16.3 & 21.2 & 24.5 & 32.0 & 9.8 & 6.5 & 7.7 & \\
\hline Another race & 1.8 & 0.5 & 5.7 & 2.0 & 1.6 & 1.1 & 3.8 & \\
\hline No preference & 81.9 & 78.3 & 69.8 & 66.0 & 88.6 & 92.4 & 88.5 & $36.1 * * *$ \\
\hline \multirow[t]{2}{*}{$\begin{array}{l}\text { Difficulty speaking with } \\
\text { physician }^{\mathrm{d}}\end{array}$} & $3.3(.89)$ & $3.4(.80)$ & $3.4(.8)$ & $3.6(.86)$ & $2.8(1.0)$ & $3.5(.71)$ & 0 & $\mathrm{~F}=2.97 *$ \\
\hline & & & & & & & & $\chi^{2}$ \\
\hline $\begin{array}{l}\text { Needed interpreter for Dr. } \\
\text { visit }\end{array}$ & 33.3 & 33.3 & 40.0 & 30.8 & 0 & 0 & 0 & 1.1 \\
\hline $\begin{array}{l}\text { Frequency of interpreter for } \\
\text { physician visit }^{\mathrm{d}, \mathrm{e}}\end{array}$ & $2.5(.97)$ & $2.0(1.0)$ & $3.0(.01)$ & $3.0(.82)$ & 0 & 0 & 0 & $\mathrm{~F}=0.13$ \\
\hline Who serves as interpreter $(\%)^{f}$ & & & & & 0 & 0 & 0 & \\
\hline Health provider & 0 & 0 & 0 & 0 & 0 & 0 & 0 & \\
\hline Staff person & 33.3 & 40 & 0 & 33.3 & 0 & 0 & 0 & \\
\hline Friend or relative & 66.7 & 60 & 100.0 & 66.7 & 0 & 0 & 0 & \\
\hline Trained medical interpreter & 0 & 0 & 0 & 0 & 0 & 0 & 0 & $\chi^{2}$ \\
\hline Someone else & 0 & 0 & 0 & 0 & 0 & 0 & 0 & 0.60 \\
\hline Person usually available to help ${ }^{f}$ & 37.5 & 75 & 0 & 0 & 0 & 0 & 0 & 4.80 \\
\hline
\end{tabular}

Note: $\mathrm{C}=$ Chinese, $\mathrm{V}=$ Vietnamese, $\mathrm{K}=$ Koreans, $\mathrm{F}=$ Filipino, $\mathrm{I}=$ Indian, $\mathrm{J}=$ Japanese

${ }^{\mathrm{a}}$ Where, $1=$ very often, $2=$ somewhat often, $3=$ not too often, $4=$ not at all

${ }^{\mathrm{b}}$ Where $1=$ very easy, $2=$ somewhat easy, $3=$ not too easy, $4=$ not at all easy, $5=$ Don't look for quality

${ }^{\mathrm{c}}$ Where $1=$ very easy, $2=$ somewhat easy, $3=$ not too easy, $4=$ not at all easy, $5=$ Don't get any information

${ }^{\mathrm{d}}$ Where $1=$ always, $2=$ usually, $3=$ sometimes, $4=$ never

${ }^{\mathrm{e}} \mathrm{Based}$ on those who needed an interpreter

${ }^{\mathrm{f}}$ Based on those who used an interpreter

${ }^{*} \mathrm{p}<.05 ; * * \mathrm{p}<.01 ; * * * \mathrm{p}<.001$ 


\section{Appendix E}

Final Logistic Regression: Predictor Variables of Screening Within the Last Two Years

\begin{tabular}{|c|c|c|c|}
\hline & Coefficient(SE) & Odds Ratio & 95\% C.I. \\
\hline \multicolumn{4}{|l|}{ Physical Exam $(n=2490)$} \\
\hline Health information from books/printed material & $.30(.09)$ & $1.35^{* * *}$ & $1.1,1.6$ \\
\hline Health information from Community Health Fair & $.41(.18)$ & $1.51^{*}$ & $1.1,2.1$ \\
\hline Ease of finding information about quality Drs. in Community & $.39(.05)$ & $1.47^{* * *}$ & $1.3,1.6$ \\
\hline Constant & -3.05 & & \\
\hline \multicolumn{4}{|l|}{ Colon Cancer $(\mathrm{n}=840)$} \\
\hline Health information from books/printed material & $.33(.15)$ & $1.39^{*}$ & $1.0,1.8$ \\
\hline Health information from Dr/other HC Provider & $.51(.17)$ & $1.66^{* *}$ & $1.2,2.3$ \\
\hline Ease of finding information about quality Drs. in Community & $.25(.08)$ & $1.28^{* * *}$ & $1.1,1.5$ \\
\hline Constant & -0.13 & & \\
\hline \multicolumn{4}{|l|}{ Prostate Cancer $(n=285)$} \\
\hline Health information from a pharmacist & $.78(.34)$ & $2.19^{* *}$ & $1.1,4.3$ \\
\hline Constant & -2.63 & & \\
\hline \multicolumn{4}{|l|}{ Pap Test $(\mathrm{n}=1517)$} \\
\hline Health information from World Wide Web & $.75(.17)$ & $2.12^{* * *}$ & $1.5,2.9$ \\
\hline Health information from Friends/Family & $.36(.14)$ & $1.40^{* *}$ & $1.1,1.9$ \\
\hline Constant & -3.50 & & \\
\hline \multicolumn{4}{|l|}{ Mammogram $(n=556)$} \\
\hline Health information from books/printed material & $.66(.23)$ & $1.93^{* *}$ & $1.2,3.0$ \\
\hline Ease of finding information about quality Drs. in Community & $.44(.11)$ & $1.55^{* * *}$ & $1.24,1.93$ \\
\hline Constant & -3.35 & & \\
\hline
\end{tabular}

$* \mathrm{p}<.05, * * \mathrm{p}<.01, * * * \mathrm{p}<.001$ 